As a preliminary contribution to our knowledge of the food fishes of Hong Kong this book is most valuable. It is greatly to be hoped, however, that it merely heralds the inauguration of a much more farreaching and systematic study of the marine resources of the Hong Kong region, to be undertaken by or under the auspices of the University; or, better still, by a specially built and properly equipped fisheries research laboratory.

\section{The Lighting of the Western World Fair}

THE illumination of the San Francisco PanamaPacific Exposition of 1915 set a high standard in exhibition lighting which was for long unsurpassed. According to an article on the Golden Gate Exposition, which appeared in the Electrician of January 20, it will be far surpassed by this new exhibition on Treasure Island in San Francisco Bay which will be opened on February 15. The gem-like appearance of the various buildings is mainly due to the use of an inexpensive insulating material called 'vermiculite - an alteration of mica expanded by electric heat to fifteen to twenty times its original size. Applied to wet stucco, vermiculite imports an antique finish which scintillates with light. The sea wall and roadway lighting of Treasure Island is designed to be in keeping with the main project, and it is considered that it will establish a new milestone in the history of illumination. Projectors concealed in troughs floodlight the walls in white. Cylindrical golden amber lanterns are spaced on approximately sixty-foot centres along the entire facade for roadway illumination and to break up the flatness of the long lighted. wall. Spectacular lighting has been arranged for the Courts of Pacifica and of the Seven Seas. The sculptured relief work consisting of submarine scenes is painted with paints that fluoresce under the ultraviolet light provided by concealed projectors from below. Nearly three hundred ultra-violet mercury floodlights, each of 100 watts capacity, are being used for fluorescence effects on outdoor murals. More than two hundred underwater floodlights are being installed, and altogether the outdoor lighting equipment comprises more than 10,000 units. The interiors of exhibition buildings are uniformly lighted by day and night; they have no windows. At the high points of the main buildings a concentrated type of reflector is employed while at lower points reflectors with layer spread are used. The total illumination of the 400 acre exposition site is estimated to require 40 million kilowatt hours during the 288 days the fair will be open.

\section{Standard Television Terms}

Now that television broadcasting has become a public service in Great Britain, it is very desirable that, so far as possible, standardized terms and definitions should be used in connexion with the technique of this subject. The British Standards Institution has already made some progress in the matter in so far as the "Glossary of Terms used in Electrical Engineering"' (No. 205-1936) contains two sub-sections dealing with terms used in connexion with television and with cathode ray tubes re- spectively. More recently, the Radio Manufacturers' Association has given consideration to the desirability of television equipment manufacturers and television engineers using a common form of nomenclature. It has been decided that, so far as possible, the technical terms given in the above Glossary should be used by manufacturers in their literature and in any instruction classes which they may operate. In addition, the Association has compiled a list of titles which are recommended for use in working the controls of television receivers. Fourteen titles are listed and described, and in so far as the modern receiver may have upwards of six hand controls directly accessible to the user, this would seem to be a very sound recommendation. It is understood that the R.M.A. has communicated the above recommendations to technical institutes providing radio engineering courses, with the view of securing their co-operation towards the desired objective.

\section{Marine Engineering Collection}

H.M. Stationery OfFice has recently published a new descriptive catalogue (price 2s. 6d. net) of the Marine Engineering Collection in the Science Museum. Nowhere else is to be seen anything like so large and representative a collection of marine engineering models, drawings, photographs, etc., as that at the Science Museum; and a close study of this catalogue and the companion volume on history and development, will repay anyone with an interest in the subject. Nearly 400 exhibits are described clearly and accurately, and there are 15 plates. Among the illustrations are photographs of the engine built by David Napier in 1811 for Henry Bell's Comet and of one set of the main steam turbines of the Queen Mary. Both these vessels were built and engined on the Clyde, but some of the most beautiful models in the collection are those of engines built on the banks of the Thames when the names of Penn, Seaward, Maudslay and Field were as widely known as those of the marine engineers of the Clyde and the Tyne are to-day. In connexion with this it is perhaps permissible again to recall the debt of marine engineers to Bennet Woodcroft, who by securing the early engine built by Symington, and that of the Comet, laid the foundation of the fine series of exhibits described in this catalogue of marine engines.

\section{First-Aid Services and Air Raid Precautions}

Following the recent transfer from the Home Office to the Ministry of Health of responsibility for approving the air raid precautions schemes of local authorities in respect of first-aid posts and ambulance services, the Minister of Health has forwarded to all local authorities responsible for such schemes and to every voluntary hospital an explanatory communication (Circular 1764. H.M. Stationery Office. ld. net). There should be at least one medical man, and if possible a trained nurse, in addition to the volunteer personnel, in attendance at every aid post. An aid post should be attached, or be very close, to all hospitals which are to be used for the initial reception of casualties, and some of the smaller hospitals, 